Vol. 1 No. 2, Juni 2021, hlm. $135-140$

DOI: https://doi.org/10.33330/jutsi.v2i1.1153

Available online at http://jurnal.stmikroyal.ac.id/index.php/jutsi

\title{
SISTEM INFORMASI GEOGRAFIS SEBARAN LOKASI TITIK PETERNAKAN DI DINAS PETERNAKAN KABUPATEN ASAHAN
}

\author{
Sri Devi Dali Ansa ${ }^{1}$, Jhonson Efendi Hutagalung ${ }^{2 *}$, Rohminatin $^{3}$ \\ ${ }^{1}$ Mahasiswa Prodi Sistem Informasi, STMIK Royal \\ ${ }^{2}$ Prodi Teknik Komputer, STMIK Royal \\ ${ }^{3}$ Prodi Sistem Informasi, STMIK Royal \\ *email : Jhonefendi12@yahoo.co.id
}

\begin{abstract}
The potential for livestock in Asahan district is very good. Besides the situation and conditions there are supportive, the geographic location of Asahan Regency also supports the District Animal Husbandry Office in the livestock sector because the area mostly covers land, so that the Asahan District Animal Husbandry Service staff in the field of livestock can help potential types of livestock based on certain areas. In addition, officers can also classify livestock birth data by district in order to increase the potential of existing livestock. The potential of livestock in Asahan district is not well managed and there is no informative mapping and monitoring that utilizes modern computer technology. Mapping and monitoring cannot be done because there is no education about the geographic information system and monitoring of the Asahan District Animal Husbandry Office and the current system is still conventional, so information about livestock does not reach the wider community, especially the Asahan area which results in a lack of knowledge. and information on the distribution of existing livestock. Therefore, the solution to increase public insight and knowledge of the potential of livestock in Asahan, a geographic information system and monitoring will be made to map the number of points of livestock distribution.
\end{abstract}

Keywords: GIS, Distribution of Farm Point Locations, PHP and MySQL

\begin{abstract}
Abstrak: Potensi ternak di kabupaten Asahan sangat bagus. Selain situasi dan kondisi disana mendukung, letak geografis kabupaten Asahan pun juga mendukung untuk Dinas Peternakan Kabupaten bidang peternakan dikarenkan wilayahnya sebagian besar meliputi daratan, sehingga petugas Dinas Peternakan Kabupaten Asahan bidang peternakan dapat membantu jenis ternak yang berpotensi berdasarkan wilayah tertentu. Selain itu petugas juga bisa mengelompokkan data kelahiran ternak per kecamatan guna meningkatkan potensi ternak yang ada.Potensi ternak di kabupaten Asahan tidak dikelola dengan baik dan belum ada pemetaan yang informatif serta monitoring yang memanfaatkan teknologi komputer modern. Pemetaan dan monitoring belum bisa dilakukan dikarenakan belum adanya edukasi tentang sistem informasi geografis dan monitoring terhadap pihak kantor Dinas Peternakan Kabupaten Asahan dan sistem yang dijalankan saat ini pun masih konvensional, sehingga informasi tentang ternak tidak sampai ke masyarakat luas khususnya wilayah Asahan yang berdampak pada minimnya pengetahuan dan informasi terhadap sebaran hewan ternak yang ada. Oleh karena itu solusi untuk meningkatkan wawasan dan pengetahuan masyarakat terhadap potensi ternak yang ada di Asahan, maka akan dibuatkan sistem informasi geografis dan monitoring untuk memetakan jumlah titik sebaran ternak.
\end{abstract}

Kata Kunci : GIS, Sebaran Lokasi Titik Peternakan, PHP dan MySQL 
Vol. 1 No. 2, Juni 2021, hlm. $135-140$

DOI: https://doi.org/10.33330/jutsi.v2i1.1153

Available online at http://jurnal.stmikroyal.ac.id/index.php/jutsi

\section{PENDAHULUAN}

Perkembangan sistem informasi memiliki banyak cabang salah satunya sistem informasi geografis. Dimana sistem lebih berfokus pada geografis. Sistem Informasi Geografis adalah sebuah alat bantu manajemen informasi yang berkaitan erat dengan sistem pemetaan dan analisis terhadap segala sesuatu serta berbagai peristiwa yang terjadi di muka bumi [1].

Pemakaian sistem informasi geografis (SIG) berbasis web merupakan sesuatu yang populer di masyarakat. Kebutuhan manusia atas informasi yang menggunakan sistem informasi geografis (SIG) berbasis Web juga semakin meningkat, antara lain untuk pemilihan atau pencarian lokasi, pemetaan, perencanaan penyebaran jaringan, masalah batas-batas wilayah suatu negara, pencarian peternakan dan sebagainya [2].

Potensi ternak di kabupaten Asahan sangat bagus. Selain situasi dan kondisi disana mendukung, letak geografis kabupaten Asahan juga mendukung untuk Dinas Peternakan Kabupaten bidang peternakan dikarenkan wilayahnya sebagian besar meliputi daratan, sehingga petugas Dinas Peternakan Kabupaten Asahan bidang peternakan dapat membantu jenis ternak yang berpotensi berdasarkan wilayah tertentu. Selain itu petugas juga bisa mengelompokkan data kelahiran ternak perkecamatan guna meningkatkan potensi ternak yang ada. Hal itu ditunjukkan dari data yang masuk ke Dinas Peternakan kabupaten Asahan adalah:

Tabel 1. Data Hewan Ternak Di Kabupaten Asahan

\begin{tabular}{|l|l|c|c|c|c|c|}
\hline \multirow{2}{*}{ No } & \multirow{2}{*}{ Nama Hewan } & \multicolumn{5}{|c|}{ Tahun } \\
\cline { 3 - 7 } & & $\mathbf{2 0 1 5}$ & $\mathbf{2 0 1 6}$ & $\mathbf{2 0 1 7}$ & $\mathbf{2 0 1 8}$ & $\mathbf{2 0 1 9}$ \\
\hline 1. & Ayam Ras & 710.400 & 718.030 & 712.120 & 802.056 & 796.861 \\
\hline 2. & Itik & 55.491 & 56.099 & 57.662 & 45.885 & 57.681 \\
\hline
\end{tabular}

Sumber dari :Dinas Peternakan Kabupaten Asahan 2020

Dari data diatas menunjukkan bahwa Kabupaten Asahan sangat bepotensi terutama ternak ayam ras dan itik. Potensi ternak di kabupaten Asahan tidak dikelola dengan baik dan belum ada pemetaan yang informatif serta monitoring yang memanfaatkan teknologi komputer modern [3]. Pemetaan dan monitoring belum bisa dilakukan dikarenakan belum adanya edukasi tentang sistem informasi geografis dan monitoring terhadap pihak kantor Dinas Peternakan Kabupaten Asahan dan sistem yang dijalankan saat ini pun masih konvensional, sehingga informasi tentang ternak tidak sampai ke masyarakat luas khususnya wilayah Asahan yang berdampak pada minimnya pengetahuan dan informasi terhadap sebaran hewan ternak yang ada.

Oleh karena itu solusi untuk meningkatkan wawasan dan pengetahuan masyarakat terhadap potensi ternak yang ada di Asahan, maka akan dibuatkan sistem informasi geografis dan monitoring untuk memetakan jumlah titik sebaran ternak.

Berdasarkan uraian di atas, "Sistem Informasi Geografis Sebaran Lokasi Titik Peternakan Di Dinas Peternakan Kabupaten Asahan", sebagai penelitian. Sehingga diharapkan sistem informasi ini dapat memberikan suatu informasi mengenai potensi peternakan di Kabupaten Asahan secara optimal. 
Vol. 1 No. 2, Juni 2021, hlm. $135-140$

DOI: https://doi.org/10.33330/jutsi.v2i1.1153

Available online at http://jurnal.stmikroyal.ac.id/index.php/jutsi

\section{METODE}

Berdasarkan kerangka kerja penelitian yang telah di gambarkan di atas, maka dapat diuraikan pembahasan dalam masing-masing tahapan dalam penelitian adalah sebagai berikut ini : (1) Identifikasi Masalah, Identifikasi masalah adalah cara untuk menemukan permasalahan yang terjadi didalam proses keberlanjutan sistem kerja sehingga nanti dapat mencapai peneyelesaian masalah yang akan di temukan solusinya penanggulangannya [4]., (2) Metode Pengumpulan Data, Metode Pengumpulan Data adalah sebuah teknik atau cara yang di lakukan oleh peneliti untuk mengumpulkan sebuah bukti data. Adapun sebuah fungsi dari pengumpulan data adalah untuk memperoleh informasi yang dibutuhkan dalam rangka mencapai suatu tujuan penelitian., (3) Analisis data, Analisis data adalah suatu kegiatan mengubah data hasil penelitian menjadi informasi yang dapat digunakan untuk mengambil kesimpulan dalam suatu penelitian. Adapun cara mengambil kesimpulan bisa dengan hipotes maupun estimasi hasil., (4) Perancangan sistem, Perancangan sistem adalah sebuah kegiatan merancang dan menentukan cara mengolah sistem informasi dari hasil analisa sistem sehingga dapat memenuhi kebutuhan dari pengguna termasuk diantaranya perancangan user interface., (5) Pembuatan Sistem, Setelah dirancang sdelanjutnya sistem akan membuat berdasarkan perancangan tersebut. Sistem ini dibuat dengan menggunakan bahasa pemrograman., (6) Pengujian Sistem, Pengujian sistem adalah pengujian program perangkat lunak yang lengkap dan terintegrasi. Perangkat lunak atau yang sering dikenal dengan sebutan software hanyalah satuan elemen dari sistem berbasis komputer yang lebih besar. Setelah sistem dibuat maka tahap selanjutnya adalah pengujian sistem yang dilakukan dengan menguji dan mengecek apakah fungsi dari sistem yang dibuat bekerja dengan baik., (7) Implementasi Sistem, Implementasi Sistem adalah prosedur yang dilakukan untuk menyelesaikan desain yang ada dalam dokumen yaitu desaian sistem yang disetujui,serta menguji, menginstal, memulai, serta menggunakan sistem yang baru atau yang sudah diperbaikin. sistem ini adalah tahapan untuk mengetahui akan berhasil atau tidaknya suatu sistem aplikasi yang dibangun.

\section{HASIL DAN PEMBAHASAN}

Penelitian ini membahas tentang Sistem Informasi Geografis (SIG) Sebaran lokasi titik peternakan Di Dinas Peternakan Kabupaten Asahan merupakan sebuah sistem yang dapat memberikan informasi mengenai lokasi-lokasi tempat umum dalam ruang lingkup pemerintahan kota Asahan dalam bentuk geografis dengan memanfaatkan peta dari Google Maps. Aplikasi GIS pencarian lokasi titik peternakan dapat memberikan informasi nama usaha ternak, jenis hewan ternak, desa serta informasi sederhana tentang tempat tersebut.

Aplikasi dapat diakses dengan koneksi internet dimanapun berada. Analisis ini merupakan suatu data spasial sistem informasi geografis yang berisi informasi lokasi (informasi spasial) contohnya adalah informasi lintang dan bujur, termasuk diantaranya informasi datum dan proyeksi. Contoh lain dari informasi spasial yang bisa digunakan untuk mengidentifikasikan lokasi misalnya adalah kode pos.

Sedangkan informasi atribut (deskriptif) biasa disebut juga dengan informasi non-spasial. Suatu lokalitas bisa mempunyai beberapa atribut atau properti yang 
Vol. 1 No. 2, Juni 2021, hlm. $135-140$

DOI: https://doi.org/10.33330/jutsi.v2i1.1153

Available online at http://jurnal.stmikroyal.ac.id/index.php/jutsi

berkaitan dengannya; contohnya jenis ternak, nama pengusaha, dan lain-lain. Sistem informasi geografis pemetaan letak sebagai media untuk memberi mencari lokasi peternakan adalah sebagai berikut pada Tabel 2 dan Tabel 3.

Tabel 2. Sebaran Lokasi Titik Peternakan Ayam Ras di Kabupaten Asahan

\begin{tabular}{|c|l|l|c|c|}
\hline & \multicolumn{2}{|c|}{ Data Lokasi } & \multicolumn{2}{c|}{ Data Spasial } \\
\hline No & \multicolumn{1}{|c|}{ Nama Usaha Ternak } & \multicolumn{1}{c|}{ Alamat } & Lat & Long \\
\hline 1 & PT. Eldira Fauna Asahan & Desa Hessa Air Genting & 2.927955 & 99.674229 \\
\hline 2 & PT. Tomo Agro Farm & Desa Hessa Air Genting & 2.918093 & 99.672765 \\
\hline 3 & PT. Unggas Raya & Desa Hessa Air Genting & 2.929844 & 99.692682 \\
\hline 4 & PT. Ciomas Raya & Desa Hessa Air Genting & 2.917362 & 99.675326 \\
\hline 5 & PT. Primatama Karya Persada & Desa Hessa Air Genting & 2.929630 & 99.692491 \\
\hline 6 & Apan Farm & Desa Hessa Air Genting & 2.923723 & 99.677839 \\
\hline 7 & Aneka Unggas & Desa Hessa Air Genting & 2.930202 & 99.694745 \\
\hline 8 & Evi Farm & Huta Padang & 2.784463 & 99.250335 \\
\hline 9 & Ahmat Faris & Desa Air Teluk Hessa & 2.873117 & 99.668172 \\
\hline 10 & Ternak Jaya Poultry Shop & Sei Alim Ulu & 2.807329 & 99.615482 \\
\hline 11 & Adiguna Farm & Sentang & 2.964524 & 99.651070 \\
\hline 12 & Hermina Farm & Huta Padang & 2.782259 & 99.247994 \\
\hline 13 & Ternak ayam Qadi & Sidomulyo, Bunut Barat & 2.997405 & 99.581268 \\
\hline 14 & Hardi Awan & Serdang, Meranti & 3.078136 & 99.627591 \\
\hline 15 & Sugiran Farm & Danau Sijabut, Air Batu & 2.890216 & 99.657953 \\
\hline
\end{tabular}

Tabel 3. Sebaran Lokasi Titik Peternakan Itik di Kabupaten Asahan

\begin{tabular}{|c|l|l|c|c|}
\hline No & \multicolumn{1}{|c|}{ Nama Usaha Ternak } & \multicolumn{1}{|c|}{ Alamat } & Lat & Long \\
\hline 1 & PT. Eldira Fauna Asahan & Desa Hessa Air Genting & 2.927955 & 99.674229 \\
\hline 2 & PT. Unggas Raya & Desa Hessa Air Genting & 2.929844 & 99.692682 \\
\hline 3 & PT. Primatama Karya Persada & Desa Hessa Air Genting & 2.929630 & 99.692491 \\
\hline 4 & Aneka Unggas & Desa Hessa Air Genting & 2.930202 & 99.694745 \\
\hline
\end{tabular}

Hasil dari setiap tampilan program dibuat dan pengkodeannya dalam bentuk file program. Pada penerapan sistem informasi geografis sebaran lokasi titik peternakan di Kabupaten Asahan dibuatlah implementasi antar muka pada admin. Berikut tampilan antar muka dari program yang telah dibuat untuk admin.

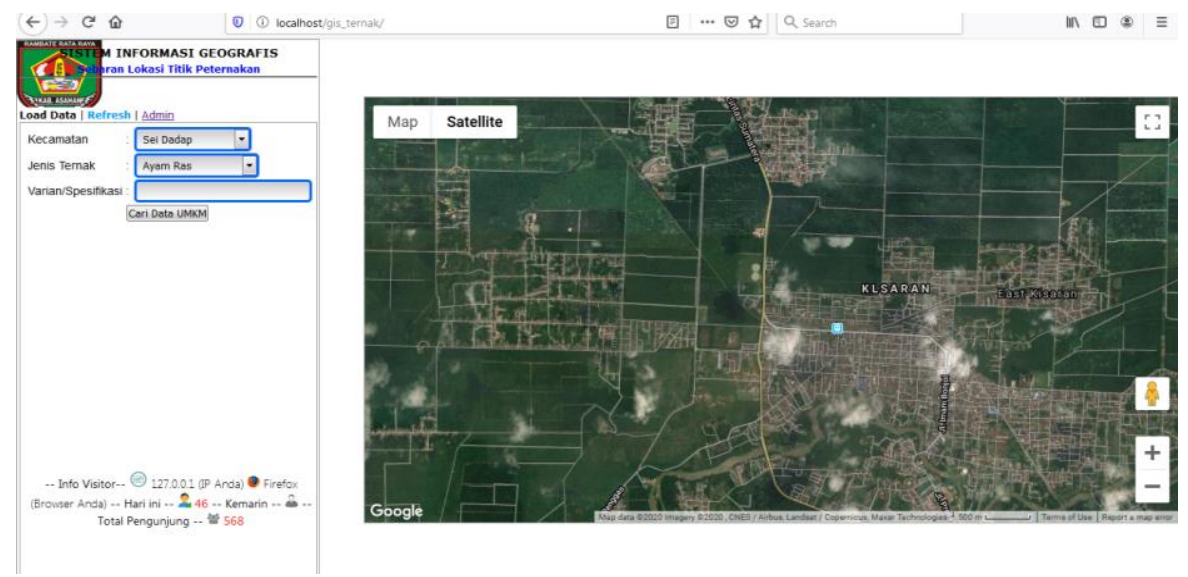

Gambar 1. Tampilan Menu Utama 
Vol. 1 No. 2, Juni 2021, hlm. $135-140$

DOI: https://doi.org/10.33330/jutsi.v2i1.1153

Available online at http://jurnal.stmikroyal.ac.id/index.php/jutsi

Sub menu form input data lokasi digunakan untuk menampilkan data lokasi titik hewan ternak. Tampilannya seperti pada gambar 2 .

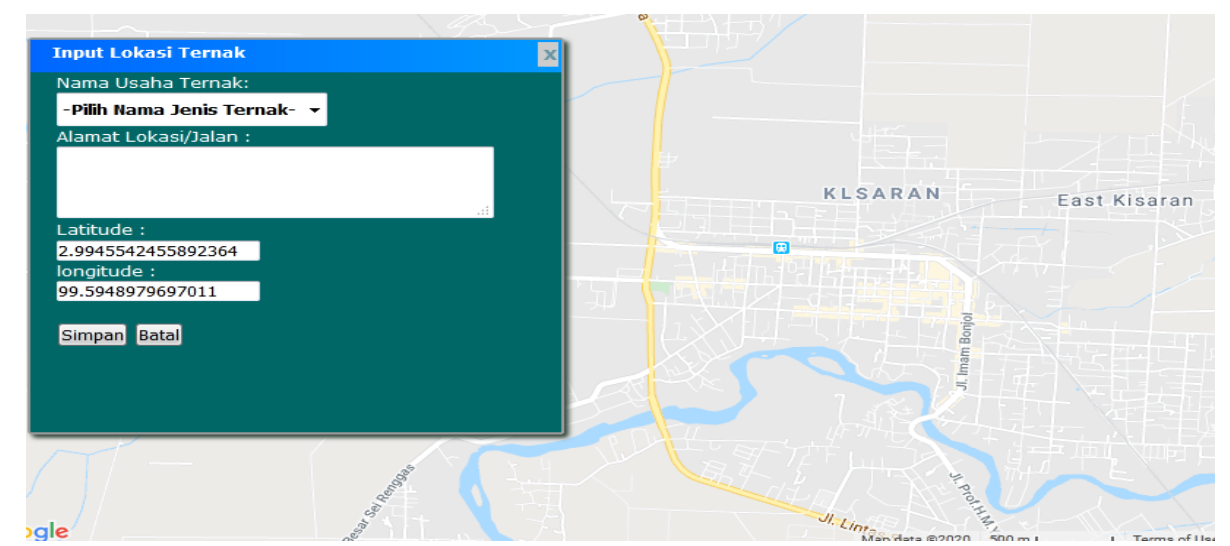

Gambar 2. Halaman Input Data Lokasi Titik Hewan Ternak

Sub menu hasil atas pencarian dapat dilakukan pada kota pencarian yang akan diarahkan langsung ke lokasi tujuan. Tampilannya seperti pada gambar 3.

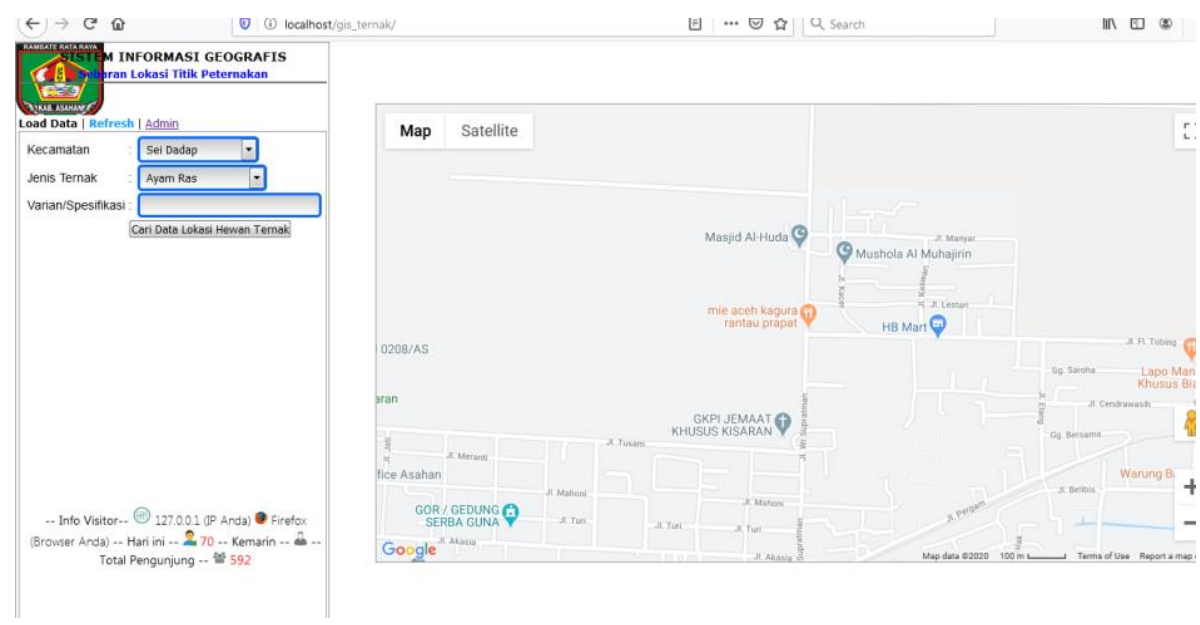

Gambar 3. Halaman Pencarian Lokasi

\section{SIMPULAN}

Hasil perancangan sistem informasi geografis sebaran lokasi titik peternakan di Dinas Peternakan Kabupaten Asahan dapat memberikan informasi kepada pemakai mengenai lokasi titik lokasi peternak ayam ras dan itik. Pengguna dapat melihat lokasi titik peternakan melalui aplikasi web yang ditampilkan pada peta Google Maps API. Hasil Pencarian akan diarahkan langsung ke lokasi tujuan dan user dapat melihat detail informasi dengan mengklik marker pada peta maka sistem akan menampilkan informasi seperti nama usaha, jenis hewan ternak, daerah lokasi, jalan, deskripsi dan koordinat lokasi tersebut.Dengan adanya aplikasi sebaran lokasi titik peternakan ini di Dinas Peternakan Kabupaten Asahan memudahkan pengguna dalam mengenai lokasi sebaran 
Vol. 1 No. 2, Juni 2021, hlm. $135-140$

DOI: https://doi.org/10.33330/jutsi.v2i1.1153

Available online at http://jurnal.stmikroyal.ac.id/index.php/jutsi

lokasi titik peternakan.Aplikasi ini hanya bisa digunakan oleh pengguna yang bersistem operasi minimal windows 10 dengan difasilitasi akses internet (online).

\section{DAFTAR PUSTAKA}

[1] R. Aulia, "Pemetaan Lokasi Lkp Dan Bimbingan Belajar Di Kabupaten Asahan Berbasis Webgis," J. Teknol. Inf., vol. 3, no. 2, p. 155, 2019, doi: 10.36294/jurti.v3i2.1019.

[2] M. Minarni and A. C. Novelina, "Sistem Informasi Geografis Fasilitas Kesehatan Kota Padang Berbasis Web," J. Teknoif, vol. 5, no. 2, pp. 73-78, 2017, doi: 10.21063/jtif.2017.v5.2.73-78.

[3] T. Abdulghani and E. Ubaedilah, "Sebaran Tanah Penduduk," vol. 2, pp. 1-12, 2018.

[4] M. Susanti, "Perancangan Sistem Informasi Akademik Berbasis Web Pada Smk Pasar Minggu Jakarta,” Informatika, vol. 3, no. 1, pp. 91-99, 2016.

[5] K. Kawano, Y. Umemura, and Y. Kano, "Field Assessment and Inheritance of Cassava Resistance to Superelongation Disease 1 ," Crop Sci., vol. 23, no. 2, pp. 201-205, 1983, doi: 10.2135/cropsci1983.0011183x002300020002x. 